\title{
QUALIDADE AMBIENTAL E MINERAÇÃO: PERCEPÇÃO DE MORADORES DE CARMO DA MATA/MG
}

Andreia Maria Pinto Rabelo ${ }^{1}$

\section{Resumo:}

A inserção de estudos sobre percepção, no campo da educação ambiental, tem contribuído para a compreensão das inter-relações entre o homem e o ambiente. Parte-se do pressuposto de que as questões ambientais resultam de um processo de construção social da percepção, assim como de um processo político. Carmo da Mata, situado na Região Centro-Oeste de Minas Gerais, é um município de pequeno porte que vivencia, atualmente, a implantação de um empreendimento de exploração de grafite em sua zona rural. Buscou-se, assim, conhecer a percepção de moradores desse município acerca da mineração e da qualidade ambiental, a partir de uma pesquisa de natureza quantitativa, do tipo survey, com a aplicação de questionários à população urbana e rural. Este estudo pretende contribuir para o desenvolvimento de ações de educação ambiental, como também para as políticas públicas que devem levar em consideração a percepção da população.

Palavras-chave: Percepção ambiental. Qualidade ambiental. Educação.

\section{ENVIRONMENTAL QUALITY AND MINING: PERCEPTION OF RESIDENTS OF CARMO DA MATA/MG}

\begin{abstract}
:
The inclusion of studies on the perception of environmental education field has contributed to the understanding of the interrelationships between man and the environment. This is on the assumption that environmental issues are the result of a social perception of the construction process, as well as a political process. Carmo da Mata, located in the Midwest region of Minas Gerais, is a small city currently experiences the implementation of a graphite exploration venture in its countryside. It attempted thus know the perception of residents of this municipality about the mining and environmental quality, from a quantitative research, survey type, with the application of questionnaires to the urban and rural population. This study aims to contribute to the development of environmental education, but also for public policy that should take into account the perception of the population.
\end{abstract}

Keywords: Environmental awareness. Environmental quality. Education.

\section{CALIDAD AMBIENTAL Y MINERÍA: PERCEPCIÓN DE LOS RESIDENTES DE CARMO DE MATA/MG}

\section{Resumen:}

La inserción de estudios sobre la percepción en el campo de la educación ambiental ha contribuido a la comprensión de las relaciones entre el hombre y el medio ambiente. Se trata del supuesto de que las cuestiones ambientales son el resultado de una construcción social de la percepción, así como de un proceso político. Carmo da Mata, ubicada en la región del Medio Oeste de Minas Gerais, es una pequeña ciudad que registra, actualmente, el despliegue de una empresa de exploración de grafito en su campo. Se intentó conocer, así, la percepción de los residentes de este municipio de la minería y la calidad del medio ambiente, a partir de una investigación cuantitativa, tipo survey, con la aplicación de cuestionarios a la población urbana y rural. Este estudio tiene como objetivo contribuir al desarrollo de la educación

\footnotetext{
${ }^{1}$ Doutoranda em Sociologia pela FAFICH/UFMG.
} 
ambiental, sino también para la política pública que debe tener en cuenta la percepción de la población.

Palabras clave: Percepción ambiental. Calidad ambiental. Educación.

\section{Introdução}

O crescente avanço da sociedade industrial, sob a égide do desenvolvimento econômico, tem causado os mais variados agravos para o meio ambiente, sobretudo em relação aos recursos naturais e aos próprios seres humanos. Nessa perspectiva, desenvolvimento tem significado degradação ambiental crescente.

Ainda assim, importantes iniciativas têm procurado compatibilizar as atividades produtivas e dos recursos naturais, buscando alcançar a chamada sustentabilidade, o que significa, também, considerar os conflitos socioambientais envolvidos no processo de apropriação do espaço. Para tanto, é importante conhecer a percepção dos atores sociais sobre os agravos ambientais que lhes são impostos, partindo do princípio de que são desiguais as condições de acesso dos diferentes setores da população à proteção ambiental (DIAS, 2007).

A percepção ambiental pode ser definida como uma tomada de consciência do ambiente pelo homem, ou seja, consiste no ato de perceber o ambiente em que se está inserido, aprendendo a proteger e a cuidar dele. Cada indivíduo percebe, reage e responde diferentemente às ações sobre o ambiente em que vive. As respostas ou manifestações daí decorrentes são resultados das percepções (individuais e coletivas), dos processos cognitivos, julgamentos e expectativas de cada pessoa (FERNANDES et al., 2003).

Para Marin (2008), a inserção da temática da percepção ambiental em pesquisas no campo da educação ambiental deve dedicar-se a pensar a natureza e as formas de relação do ser humano com as realidades imediatas, nas quais se inserem a coletividade e o lugar habitado. Além disso, deve refletir sobre as formas como essa relação é influenciada por conhecimentos e discursos construídos socialmente, importando, também, o entendimento dos processos históricos e culturais dessa construção, nas investigações sobre representação social.

O presente estudo, ao focalizar a análise da percepção ambiental, parte do pressuposto de que questões ambientais são, elas próprias, resultados de um processo de construção social da percepção. Entretanto, não desconsidera a problemática ambiental como um processo político e, como tal, essencialmente conflituoso (ALONSO; COSTA, 2002). Dessa forma, a percepção dos moradores acerca de seu ambiente é importante para se compreender melhor as inter-relações entre o homem e o ambiente, suas expectativas, anseios, satisfações e insatisfações, julgamentos e condutas, podendo, assim, ser utilizada como subsídio para o planejamento de ações no campo da educação ambiental.

Carmo da Mata, situado na Região Centro-Oeste de Minas, é um município de pequeno porte no qual está em processo de licenciamento um empreendimento de exploração de grafite, em sua zona rural. A instalação dessa atividade abre uma perspectiva econômica significativa para o município, que apresenta pouca diversificação econômica.

Nesse sentido, o presente estudo buscou conhecer a percepção de moradores de Carmo da Mata, tanto da população urbana quanto da rural, sobre essa atividade e a qualidade ambiental do município. Ressalta-se que a população rural escolhida reside na comunidade de Quilombo, localizada próxima ao empreendimento a ser instalado. Este estudo pretende contribuir para o desenvolvimento de ações locais de educação ambiental, como também para o desenvolvimento de políticas públicas que levem em consideração às expectativas da população local. 


\section{Materiais e métodos}

\subsection{Caracterização da área de estudo}

O município está localizado na Mesorregião Oeste de Minas Gerais, microrregião de Oliveira. Integra a Região de Planejamento do Centro-Oeste de Minas e a Região Administrativa do Alto São Francisco. Conta com uma população de 10.927 habitantes e uma taxa de urbanização de 78,8\%.

Em termos de distribuição do PIB por setores econômicos, predomina o setor de serviços $(70,4 \%)$, seguido pela agropecuária $(16,5 \%)$ e, por último, a indústria $(13,1 \%)$. O setor de serviços não só é o mais importante em termos de PIB como também em geração de empregos.

As atividades econômicas de Carmo da Mata são pouco diversificadas, com maior concentração numérica de empresas nos setores da indústria de transformação (14\%) e comércio, reparação de veículos automotores e motocicletas (49\%) (IBGE, 2010).

Em Carmo da Mata observa-se uma boa situação em relação ao acesso a serviços de água e lixo, que atendem, respectivamente, a 96,1\% e 98,7\% dos domicílios, ainda que com grandes desafios em relação à proteção e preservação das águas, especialmente pela contaminação pelo esgoto. Informações do Zoneamento Ecológico Econômico do Estado de Minas Gerais - ZEE (MINAS GERAIS, 2008) indicam que os recursos hídricos do município são vulneráveis, especialmente nos quesitos relativos à contaminação e disponibilidade de água subterrânea.

Além do problema da contaminação por esgotos, os cursos d'água no município também são degradados devido às atividades econômicas locais. Nas partes mais baixas do município estão localizadas as regiões aptas à exploração mineral e as áreas de explorações agrícolas que são conduzidas, em boa parte, sem o emprego de práticas conservacionistas, possibilitando, assim, o carreamento de solos para os cursos de águas e para o aparecimento de áreas com processo de erosão laminar e em sulcos. Com relação às matas ciliares, verificase que são bastante reduzidas (FUNEDI, 2009). ${ }^{2}$

No que se refere aos resíduos sólidos, Carmo da Mata possui uma área, de propriedade da municipalidade, onde estão instaladas uma usina de triagem e compostagem e um aterro de rejeitos. A coleta atende a $98,7 \%$ dos domicílios, indicando a universalização desse serviço público na área urbana.

\subsection{Metodologia}

Neste estudo foi realizada uma pesquisa de natureza quantitativa, do tipo survey, utilizando um formulário padronizado para a coleta de dados, com questões abertas e fechadas. Admitindo-se um coeficiente de segurança de $90 \%$ e margem de erro de $8 \%$, a amostra da pesquisa foi constituída por 92 moradores, de 18 anos ou mais, estratificada por local de residência (urbano e rural) e sexo, com base nos dados do Censo Demográfico de 2010 .

O questionário abordou questões relativas às características do respondente, problemas do município, avaliação das condições ambientais, conhecimento sobre a atividade

2 FUNDAÇÃO EDUCACIONAL DE DIVINÓPOLIS. Diagnóstico Participativo de Carmo da Mata/MG. Divinópolis. Centro de Referência Técnica em Extensão, Pesquisa e Pós-graduação, 2009. 148 f. Não publicado. 
mineradora e seus impactos e potencialidades, participação social e hábitos de comunicação. ${ }^{3}$ O trabalho de campo foi realizado observando-se procedimentos que envolveram pré-teste, a constituição e treinamento da equipe de pesquisa e logística do trabalho de campo. A coleta de dados ocorreu nos meses de março e abril de 2015.

\section{Resultados e Discussão}

\subsection{Perfil dos entrevistados}

O perfil dos entrevistados caracteriza-se pela predominância de mulheres $(53,3 \%)$, conforme se verifica, também, na população total do município, segundo o Censo do IBGE/2010.

Quanto à faixa etária, os entrevistados, em sua maioria, são adultos na faixa dos 25 a 59 anos $(67,4 \%)$, tanto na área urbana quanto rural. Jovens e idosos estão representados na pesquisa, somando, respectivamente, $10,9 \%$ e $21,7 \%$.

Em termos de escolaridade, a parcela mais significativa dos entrevistados, 59,8\%, não tem educação básica, ou seja, não completou o ensino médio. Nesse universo, destacam-se $19,6 \%$ que podem ser considerados analfabetos funcionais, uma vez que se declararam analfabetos ou não concluíram as quatro primeiras séries do ensino fundamental. Outros $29,3 \%$ possuem ensino médio e $10,9 \%$, ensino superior.

Entre os entrevistados predomina uma renda familiar baixa: $66,3 \%$ deles têm renda de até 3 salários mínimos. Com mais de 3 a 5 salários estão 20,6\%, de 5 a 10 salários, 8,7\%, e mais de 10 salários, apenas 3,3\%. A ocupação dos entrevistados foi bastante variada, destacando-se donas de casa $(18,4 \%)$, aposentados e pensionistas $(22,3 \%)$.

\subsection{Problemas do município}

Os moradores foram questionados sobre quais seriam os problemas do município. As respostas apresentadas foram organizadas por temas e podem ser visualizadas na Figura 1.
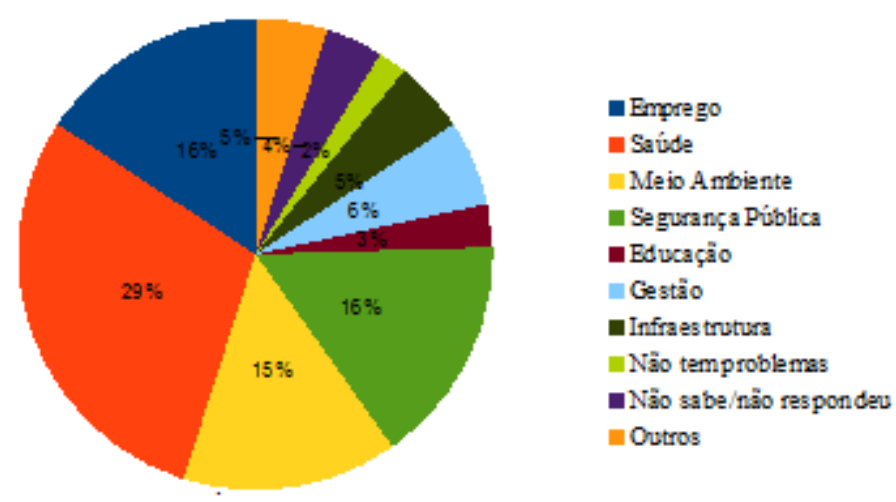

Figura 1 -Problemas do município por áreas temáticas Fonte: Pesquisa de Campo

Entre os problemas apresentados, destacaram-se os relativos à saúde (29\%), emprego (16\%) e segurança pública (16\%) e meio ambiente (15\%). Com relação aos problemas

3 A elaboração deste questionário foi inspirada pela pesquisa Caracterização Ambiental por Percepção, realizada pela SOS Mata Atlântica, Instituto Paulo Montenegro e parceiros. 
ambientais, todos foram apresentados pelos moradores urbanos, que indicaram, principalmente, a poluição e a sujeira das ruas e lotes vagos.

Pode-se afirmar que os problemas ambientais, na percepção dos moradores, aparecem de forma pouco significativa. Segundo Fuks (1998), críticos do caráter universalista do meio ambiente, enquanto problema social, afirmam que ele não se apresenta como questão relevante para as classes sociais que ainda não têm asseguradas as condições básicas de sobrevivência, o que explicaria sua presença pouco significativa na percepção local. Contudo, o mesmo autor ressalta que "a definição de meio ambiente enquanto problema social não é apenas resultado de uma universalidade conceitualmente deduzida, mas depende, igualmente, de disputas localizadas" (FUKS, 1998, p. 8). Dessa forma o autor chama a atenção para uma articulação entre o universal e o particular na definição do meio ambiente enquanto problema social, ressaltando a importância da dinâmica local nesse processo.

Nessa medida, a presença pouco significativa do meio ambiente na percepção dos moradores, aponta para a necessidade de uma educação ambiental crítica, capaz de provocar reflexões sobre como as dimensões de reprodução da vida material e da relação do homem com o ambiente se articulam, compreendendo um processo eminentemente político, que visa ao desenvolvimento de uma consciência crítica (LAYRARGUES, 2002).

Outra questão investigada junto aos moradores refere-se aos problemas ambientais do município. Com essa questão, os moradores foram provocados a pensar sobre esse tema especificamente, ainda que se considere que o ambiente se refira a tudo que os rodeia. $\mathrm{O}$ principal problema apontado relaciona-se ao lixo $(23,6 \%)$, o que se repete tanto na área urbana $(23 \%)$ quanto rural $(27,9 \%)$.

A questão do lixo vem sendo apontada pelos ambientalistas como um dos mais graves problemas ambientais urbanos da atualidade, a ponto de ter-se tornado alvo privilegiado de programas de educação ambiental na escola brasileira (LAYRARGUES, 2002) e um dos principais temas ambientais nos meios de comunicação de massa, especialmente a TV. Esta centralidade no debate ambiental tem sido acompanhada de uma abordagem reducionista, pragmática e pouco crítica, focalizada nos aspectos técnicos, psicológicos e comportamentais em detrimento dos políticos (LAYRARGUES, 2002). Dessa forma, ainda que seja positiva a presença dessa problemática na percepção da população, é desejável que isto não aconteça de forma acrítica ou reduzindo a questão ambiental ao tema do lixo, como uma camuflagem ou esquiva de outros problemas também relevantes.

Entre os problemas ambientais que foram apresentados pelos moradores estão, também, o esgoto (10\%) e poluição do ar (10\%), ainda que menos significativamente. Cabe lembrar que o município não dispõe de tratamento de esgoto e que a indústria de transformação é a principal atividade industrial, com destaque para a fundição. A fundição se caracteriza tanto pela demanda de recursos naturais quanto pela produção de resíduos sólidos e de poluição atmosférica, embora se saiba que não existe atividade industrial que não gere impactos no meio ambiente, ainda que mínimos.

Ressalta-se que uma parcela significativa dos entrevistados $(8,6 \%$ do total $)$, especialmente na área rural (27,9\% dos moradores rurais), afirmou que o município não tem problemas ambientais e outros $5,6 \%$ não souberam ou não responderam, o que sinaliza uma percepção pouco crítica desses atores sobre a temática ambiental. A despeito de uma crescente incorporação da discussão ambiental pela sociedade, no que alguns autores denominam de surgimento de uma sensibilidade ecológica, ainda existem pessoas que consideram o lugar que habitam como livre de problemas ambientais ou que desconhecem a questão, demonstrando o desafio do debate ambiental em nível local.

Quando questionados sobre os responsáveis pelos problemas ambientais, os moradores indicaram, principalmente: a população (32\%), a Prefeitura (26\%) e os proprietários de empresas $(11 \%)$. A pesquisa não permitiu aprofundar a questão da responsabilização, mas 
uma expressividade de apontamentos para o papel da população nos problemas ambientais está coerente com estudos que indicam uma tendência na discussão ambiental, especialmente na educação ambiental tradicional, de uma exacerbada ênfase individualista e de conscientização, centrada na mudança de comportamentos (comportamentalismo) e no conhecimento dos aspectos meramente ecológicos para manutenção e preservação de ecossistemas (preservacionista) (LOUREIRO, 2012). Essa perspectiva considera a atuação de atores sociais individuais e uma responsabilização generalizada pelos problemas ambientais, desconsiderando a desigual apropriação dos recursos e distribuição dos custos ambientais.

\subsection{Qualidade ambiental}

A pesquisa também se dedicou a conhecer como os moradores avaliavam a qualidade ambiental no município, entendida como o estado das condições do meio ambiente local.

Os moradores foram solicitados a estabelecer uma comparação entre o município de Carmo da Mata e os demais da região, no que se refere ao meio ambiente. No universo total de entrevistados, uma parcela expressiva (37\%) avaliou que o município é igual aos demais em relação ao meio ambiente. Essa avaliação é reforçada, sobretudo, pelos moradores da área urbana, sendo que 42,1\% deles fizeram essa avaliação. A avaliação negativa (pior que os demais) do meio ambiente no município foi realizada por $11,9 \%$ do total de entrevistados, não havendo diferenças significativas de percentual entre moradores urbanos e rurais. A avaliação positiva (melhor que os demais) foi realizada por $15,2 \%$ dos entrevistados, sendo que nessa avaliação destaca-se um percentual mais expressivo de moradores da área rural. Também, mostrou-se relevante nessa questão o posicionamento de $35,9 \%$ dos entrevistados, que não souberam ou não a responderam, o que aconteceu, principalmente, entre os moradores da área rural $(43,9 \%)$.

Para continuar a avaliação da qualidade ambiental do município, foram apresentadas aos moradores algumas afirmativas, distribuídas pelos temas de qualidade do ar, ambiente urbano, qualidade da água, gestão de resíduos e território. A partir dessas afirmativas, os moradores deveriam responder: concordo totalmente, concordo mais ou menos, discordo ou não sabe/não respondeu.

A avaliação dos moradores acerca da qualidade da água do município revela que a principal preocupação é com a poluição dos rios por lixo e esgoto. A maioria dos moradores discorda que os rios sejam livres de lixo (59\%) e mau cheiro (52\%) e que as pessoas podem nadar, pescar e brincar neles $(59 \%)$.

Ainda com relação aos rios, uma parcela muito expressiva acredita que esses têm suas margens preservadas com árvores $(45 \%)$ e outros $29 \%$ concordam parcialmente com isso. O diagnóstico socioeconômico do município revelou o contrário, ou seja, que a degradação das matas ciliares é grande, havendo proteção dos rios pelas matas em dimensões muito reduzidas, especialmente no Ribeirão Boa Vista, importante curso d'água do município. Essas informações revelam uma percepção pouco apurada dos entrevistados acerca da problemática ambiental do município.

As avaliações mais positivas foram quanto às enchentes, das quais o município estaria livre (63\%). Além disso, a maioria dos entrevistados concorda totalmente que as pessoas no município sabem que existe relação entre a ocupação das margens e as enchentes.

Para os entrevistados, os moradores sabem que jogar lixo nas ruas e rios pode aumentar o risco de enchentes (70\%). Aqui parece haver uma contradição, uma vez que os entrevistados afirmaram que os rios estão poluídos por lixo. Contudo, sabe-se que conhecer atitudes ambientais corretas não significa adotá-las, fato que parece acontecer conforme a visão dos moradores. Isso se reforça pelo fato de que o lixo aparece como o principal problema ambiental do município, seguido pelo esgoto e poluição do ar. 
Quanto ao abastecimento de água, a percepção da maioria dos moradores é positiva: $64 \%$ dos entrevistados afirmaram que não há interrupção no abastecimento e que o manancial que abastece o município estaria livre de contaminação (48\%). O gráfico a seguir (Figura 2) demonstra as percepções dos moradores quanto à qualidade da água:

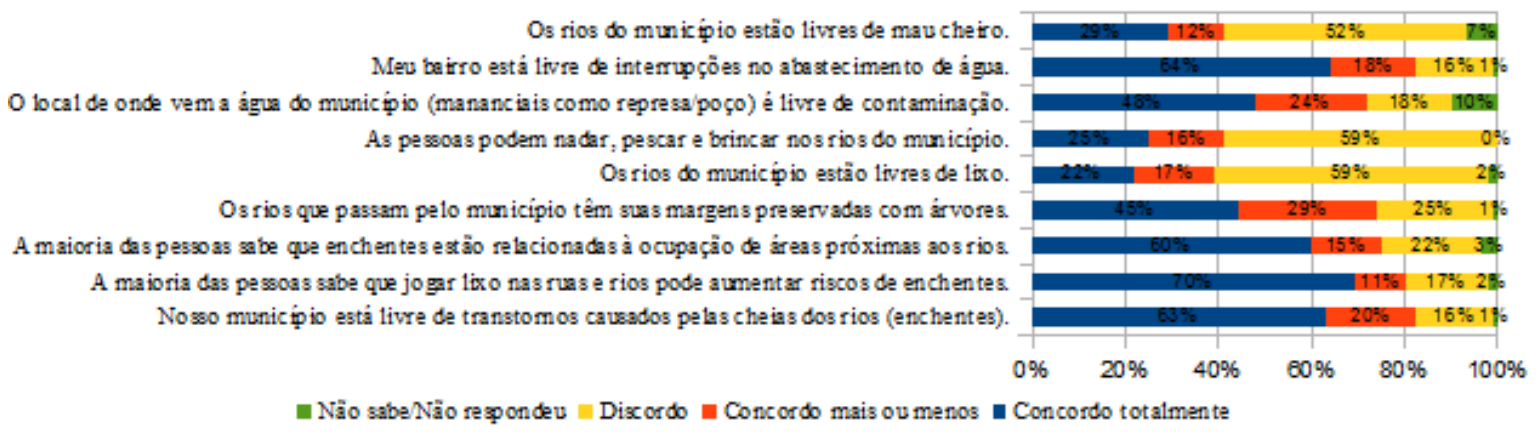

Figura 2 - Qualidade da água

Fonte: Pesquisa de Campo

A qualidade do ar no município foi avaliada como positiva: $58 \%$ dos moradores concordam que ela é boa e outros $32 \%$ concordam em parte. Ainda assim, $11 \%$ discordam, como pode ser verificado na Figura 3.

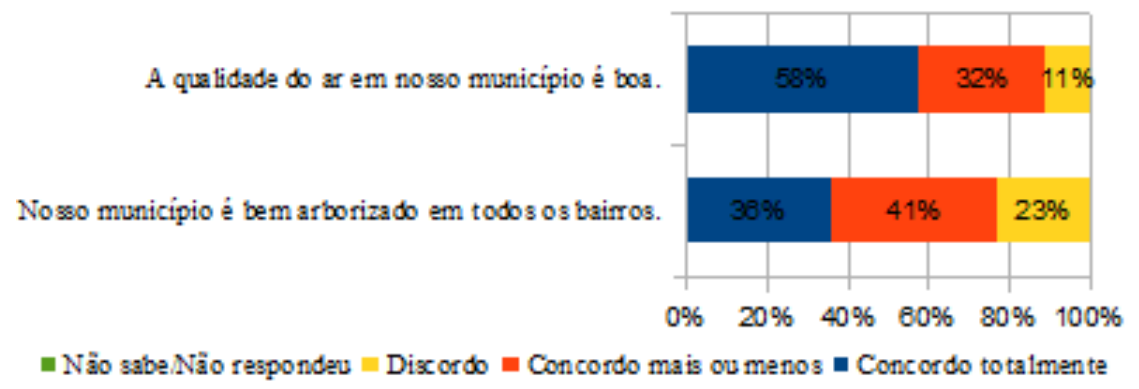

Figura 3 - Qualidade do Ar

Fonte: Pesquisa de Campo

Houve maior discordância entre os moradores quanto à arborização. Em relação à afirmativa de que o município é bem arborizado em todos os bairros, 36\% afirmaram concordar totalmente, $41 \%$ concordaram mais ou menos e $23 \%$ não concordaram. 
Os dados acerca da percepção dos moradores quanto aos resíduos sólidos (lixo) demonstram que, para a maioria dos moradores, a coleta de lixo é satisfatória, uma vez que $86 \%$ concordaram totalmente que o caminhão passa regularmente no bairro/comunidade (Figura 4).

Por outro lado, regularidade do serviço não é suficiente para garantir a limpeza urbana. Assim, 50\% dos entrevistados concordam que o bairro/comunidade está livre de contaminação pelo lixo, mas outros $17 \%$ concordam mais ou menos e outros expressivos $32 \%$ discordam. Dessa forma, esses dados sinalizam que o lixo, apresentado como o principal problema ambiental do município, não decorre da ausência ou ineficiência do poder público em seu recolhimento. Os indicativos são de que se trata de uma postura inadequada da população, como quando os entrevistados indicaram os problemas de lotes vagos sujos e a poluição e sujeira das ruas. Além disso, quando questionada sobre os responsáveis pelos problemas ambientais, a população foi a mais citada (32\% dos entrevistados).

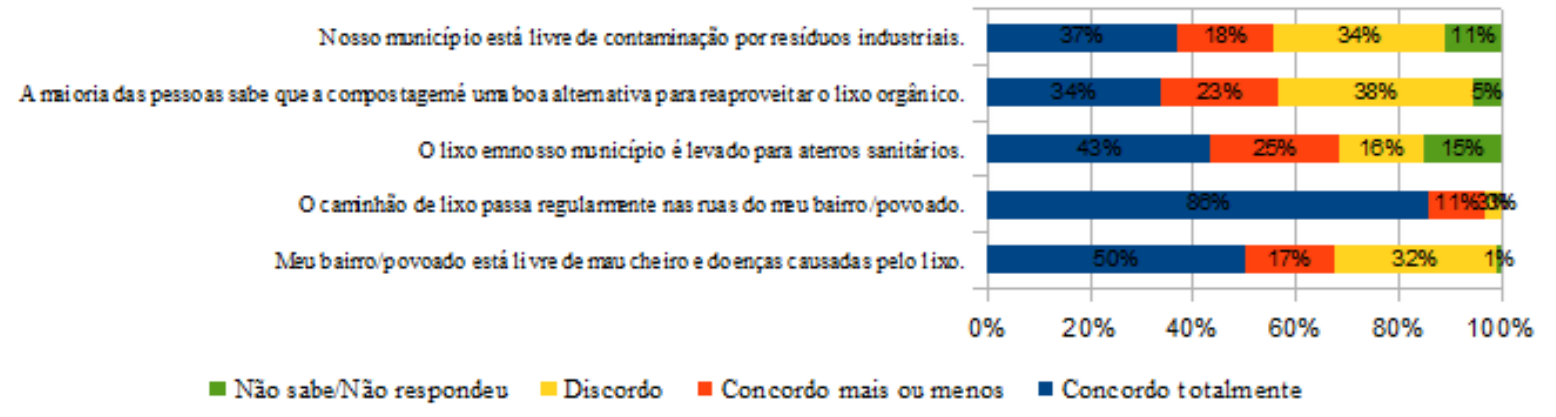

Figura 4 - Gestão de Resíduos Sólidos

Fonte: Pesquisa de Campo

Os moradores mostraram-se menos informados com relação à destinação final dos resíduos sólidos: $43 \%$ concordaram totalmente que o lixo é levado para um aterro sanitário, $25 \%$ concordaram mais ou menos, $16 \%$ discordaram e $15 \%$ não souberam ou não responderam. Cabe registrar que o município não tem um aterro sanitário, mas, sim, uma usina de triagem e compostagem e um aterro controlado, que são modalidades técnicas, muitas vezes, de difícil compreensão para a maioria da população, incapaz de distinguir entre uma e outra forma de disposição. Contudo, são formas significativamente diferentes e de impactos ambientais diversos, que precisam ser mais bem divulgadas à população.

Entre as afirmativas sobre o lixo, está a de que a maioria das pessoas sabe o que é $e$ quais os benefícios da compostagem. A maioria dos respondentes se posicionou entre concorda mais ou menos (23\%) e discorda (38\%). Outros $34 \%$ concordaram que a população conhece a compostagem e apenas $5 \%$ não souberam responder.

A questão do lixo industrial e da contaminação também foi abordada. Para 37\%, o município está livre da contaminação por resíduos industriais. Entretanto, 18\% concordaram mais ou menos e outros $34 \%$ discordaram, supondo que há possibilidade de contaminação. Expressivos $11 \%$ não responderam ou não souberam responder.

A temática do território foi abordada em seis afirmativas. Parte dessas buscou identificar a percepção dos moradores acerca da relação entre atividades econômicas e meio ambiente, como demonstrado na Figura 5. 


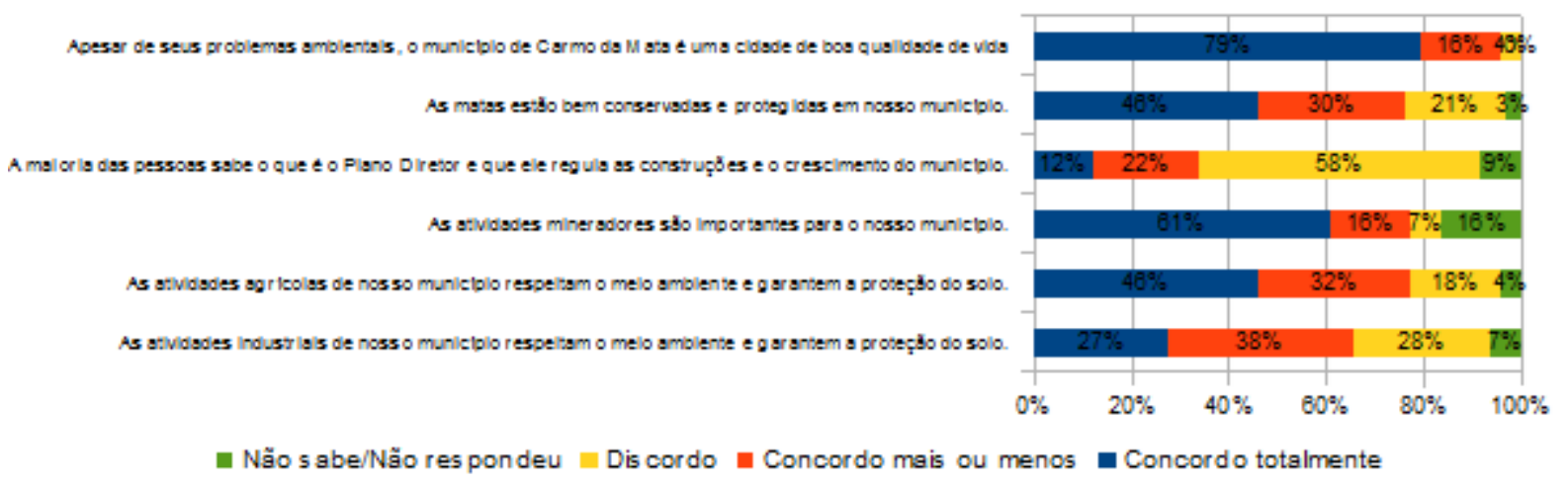

Figura 5 - O Território

Fonte: Pesquisa de Campo

As atividades agrícolas foram mais bem avaliadas do que as industriais: $46 \%$ dos entrevistados concordaram que as atividades agrícolas respeitam o meio ambiente, contra $27 \%$ com relação à indústria. Ainda em relação a essas atividades, concordaram que elas respeitam mais ou menos o meio ambiente $38 \%$ dos entrevistados, com relação à indústria e $32 \%$ com relação à agropecuária. Os que discordaram foram $28 \%$ ao avaliarem as atividades industriais e $18 \%$ ao avaliarem as atividades agrícolas.

Com relação à afirmativa de que a atividade mineradora é importante para o município, a maioria (61\%) concordou totalmente, $16 \%$ concordaram mais ou menos e apenas $7 \%$ discordaram, enquanto $16 \%$ não souberam ou não responderam.

Sobre o conhecimento da população acerca do Plano Diretor, os dados revelaram que a maioria dos entrevistados não acredita que a população de Carmo da Mata conheça o que é o Plano Diretor e seu papel (58\%). Outros 22\% dos entrevistados concordaram mais ou menos e $12 \%$ afirmaram que as pessoas têm essa informação. Não souberam responder $9 \%$. O município já tem Plano Diretor aprovado e, portanto, tem o uso e ocupação do território regulado por este instrumento jurídico-urbanístico, que ainda é desconhecido da maior parte da população.

Outra afirmativa referente à temática Território abordou a questão da preservação ambiental. Para $46 \%$ dos entrevistados as matas estão bem protegidas, diferentemente do que apontou o diagnóstico socioeconômico do município, em que $30 \%$ concordaram mais ou menos e $21 \%$ discordaram.

A última afirmativa nesse bloco foi a de que apesar de seus problemas ambientais, $o$ município de Carmo da Mata é uma cidade de boa qualidade de vida. A maior parcela dos entrevistados concordou com essa afirmação (79\%). Concordaram mais ou menos $16 \%$ e apenas 4,3\% discordaram. Isso indica que a percepção dos entrevistados é bastante positiva no que se refere à qualidade de vida em seu município, ainda que reconheçam parte de seus problemas, conforme demonstrado ao longo do estudo.

Sabe-se que a percepção ambiental, que envolve a atribuição de valores e tomada de posições, deve ser analisada tanto do ponto de vista cognitivo como do afetivo. Assim, podese entender a avaliação positiva da qualidade de vida no município também do ponto de vista afetivo, que sinaliza para a presença de um sentimento de topofilia (TUAN, 1980), ou seja, de laços afetivos dessas pessoas com o ambiente em que vivem. 


\subsection{Avaliação da atividade mineradora}

A mineração é uma atividade que visa extrair economicamente os recursos minerais da crosta terrestre e compreende a prospecção/pesquisa, desenvolvimento, lavra e beneficiamento, excluindo-se a metalurgia e a transformação. Todas as etapas da mineração devem ser realizadas de forma a garantir a continuidade da atividade e o respeito ao ambiente, o que não é uma tarefa isenta de dificuldades.

A importância da atividade se alicerça no reconhecimento de que se trata da atividade econômica responsável pela produção de bens, que atende às necessidades materiais da civilização moderna.

Os entrevistados foram questionados acerca de sua opinião sobre a implantação da atividade de mineração no Município de Carmo da Mata. Não foram oferecidas alternativas e cabia ao entrevistado, de forma livre, indicar sua resposta. A maioria das respostas foi positiva, se destacando indicações de que vai gerar mais emprego $(32,9 \%)$ e de que será ótimo ou bom (12,4\%). Essa avaliação se destacou, principalmente, na percepção dos moradores da área rural, em que os percentuais para tais respostas apresentaram-se mais elevados do que quando considerado com o total de entrevistados, conforme a Figura 6. $\mathrm{O}$ percentual de moradores que não souberam opinar ou não responderam foi elevado, chegando a $26,8 \%$ do total de entrevistados, o que sinaliza para o possível desconhecimento acerca da atividade.

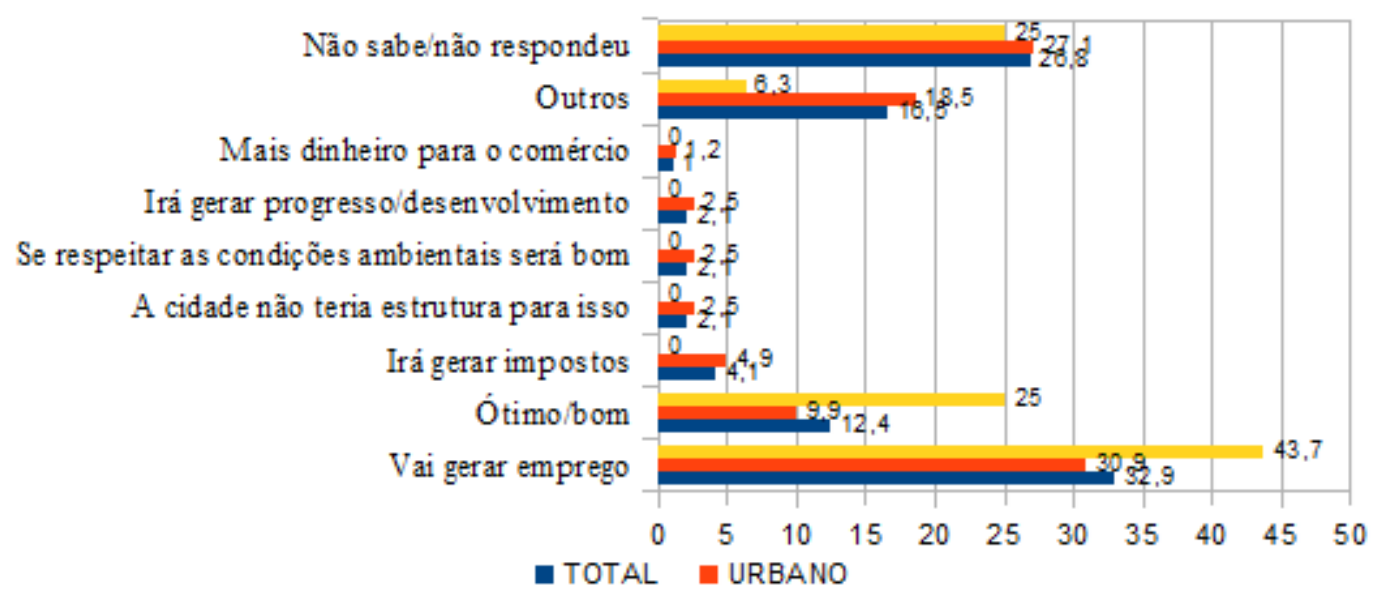

Figura 6 - Opinião dos moradores acerca da implantação de atividade mineradora no município

Fonte: Pesquisa de Campo

Dessa forma observa-se, por um lado, o desconhecimento dos moradores e, por outro, uma expectativa muito positiva com a implantação da atividade, especialmente no que se refere à geração de empregos. Além disso, a percepção dos moradores foi apenas modestamente acompanhada pelo reconhecimento dos impactos negativos da atividade, que promove devastação e poluição ambiental, quer no processo exploratório das minas, quer no pós-fechamento.

$\mathrm{Na}$ implantação de atividades mineradoras, a geração de empregos tem sido reconhecida como um impacto positivo não apenas pela população como pelo poder público e, assim, se tornado um elemento importante no aumento da influência do poder corporativo na relação da atividade com o território. Os dados da pesquisa confirmam essa situação e denotam a reprodução deste pacote interpretativo (FUKS, 1998), o que se configura como 
fenômeno de grande relevância no desdobramento da vida política local.

Ainda que se leve em consideração a geração de empregos, não se pode ignorar o fato de que a implantação de atividades mineradoras se estabelece geralmente com baixos níveis de interação com os municípios, pouco diálogo e centrada em ações de cunho paternalista, naquilo que as mineradoras entendem serem contrapartidas (CARSALADE; ABREU, 2012).

A associação entre mineração e qualidade de vida também foi investigada. No sentido de conhecer a percepção dos moradores sobre esse aspecto, eles foram assim questionados: Você acha que a mineração é uma atividade positiva ou negativa para a qualidade de vida da população? As respostas à questão podem ser visualizadas na Figura 7.

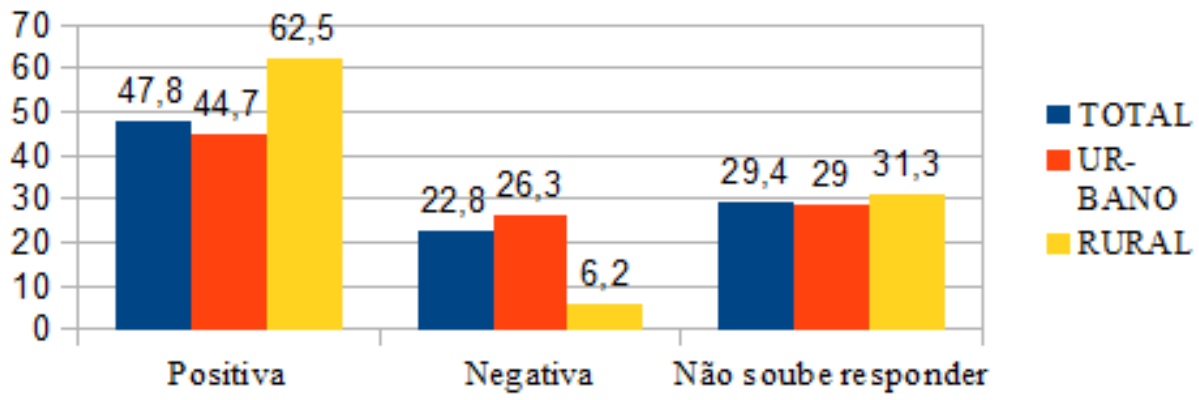

Figura 7 - Avaliação da contribuição da mineração para a qualidade de vida da população $(\%)$

Fonte: Pesquisa de Campo

Para $62,5 \%$ dos moradores, a mineração é uma atividade positiva para a qualidade de vida, para $22,8 \%$ negativa, e expressivos $29,4 \%$ não souberam ou não responderam. Em seguida, questionou-se em que sentido essa atividade seria negativa ou positiva, buscando-se compreender o sentido atribuído a ambas as respostas anteriores.

Para os que entendem a atividade como positiva (62,5\%), essa percepção está pautada, maciçamente, na capacidade da mineração de geração de emprego e renda $(57,4 \%)$. Contudo, $27,8 \%$ dos entrevistados, apesar de enxergarem na mineração a capacidade de contribuir para a qualidade de vida da população, não souberam responder quais seriam seus pontos positivos, o que demonstra um baixo grau de conhecimento dos moradores, o que pode estar correlacionado à sua baixa escolaridade, bem como à falta de acesso às informações sobre a atividade mineradora propriamente dita (Figura 8).

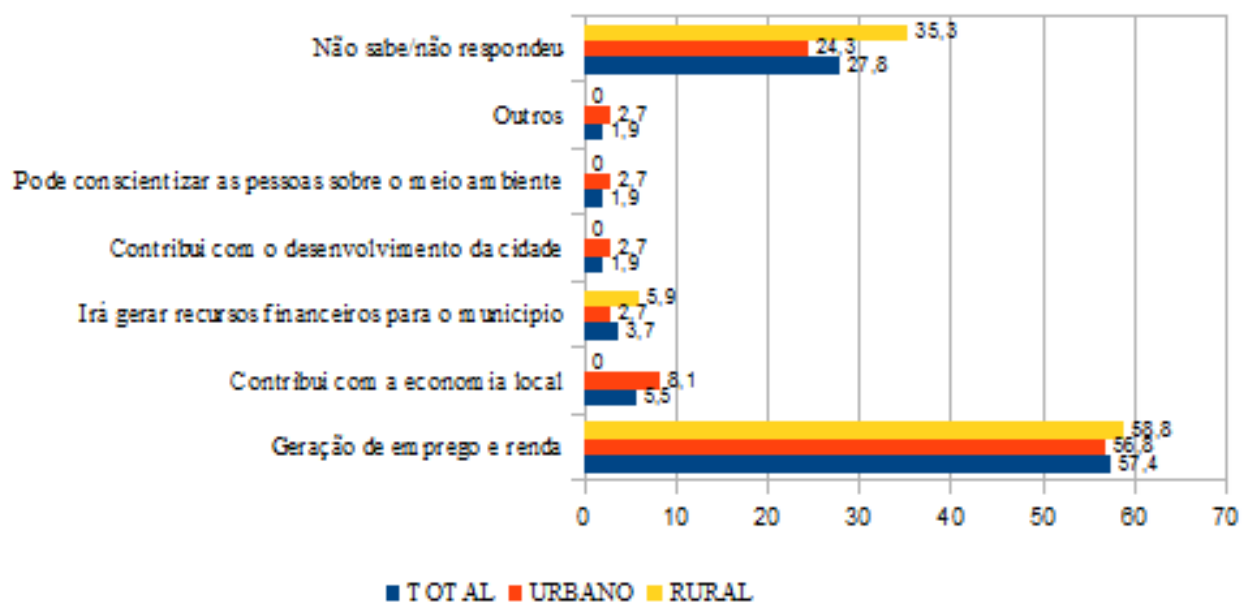

Figura 8 - Pontos positivos da mineração para a qualidade de vida da população

Fonte: Pesquisa de Campo 
Entre os entrevistados $(22,8 \%)$, apenas os da área urbana identificaram pontos negativos para a qualidade de vida da população, sendo que $80 \%$ das respostas indicaram questões ambientais como traz poluição, causa degradação ambiental, polui a água, o ar, rios e solos, provoca barulho (Figura 9).

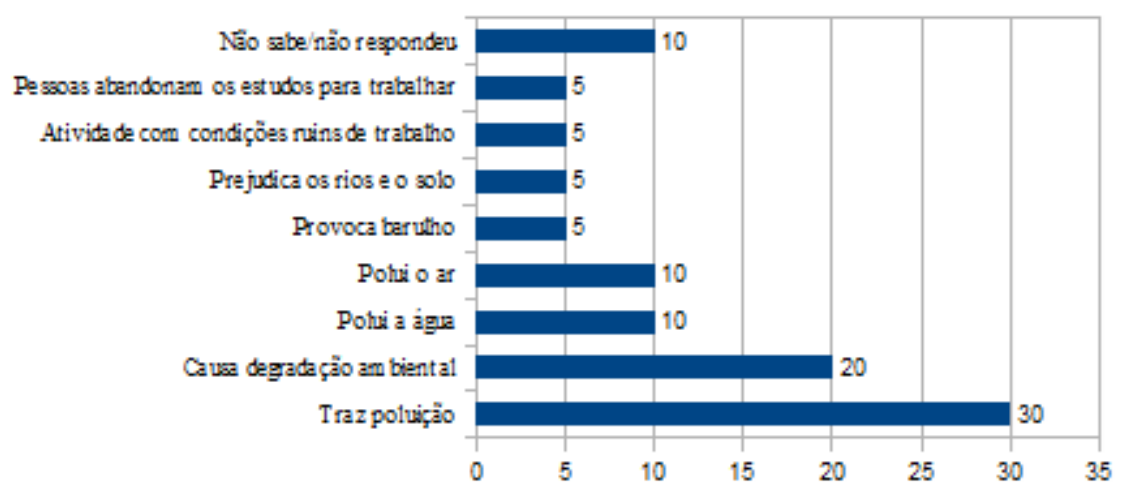

Figura 9 - Pontos negativos da mineração para a Qualidade de vida da população - área urbana (\%)

Fonte: Pesquisa de Campo

Ainda que a mineração seja atividade essencial para a sociedade, um fator claramente observado é o reconhecimento, pela sociedade, dos custos não lucrativos relacionados à extração de minérios, ou seja, aqueles relacionados principalmente às questões ambientais. Nesse contexto, investigou-se o conhecimento dos moradores sobre os impactos ambientais da mineração, cujos resultados estão expressos nas Figuras 10 e 11

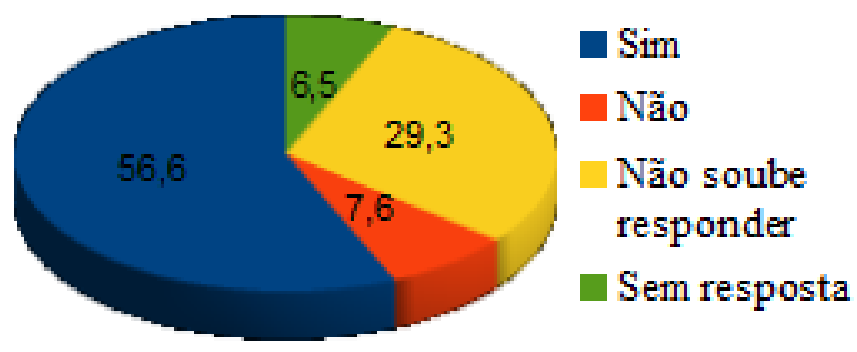

Figura 10 - Você acredita que a mineração gera impactos ao meio ambiente $(\%)$

Fonte: Pesquisa de Campo 


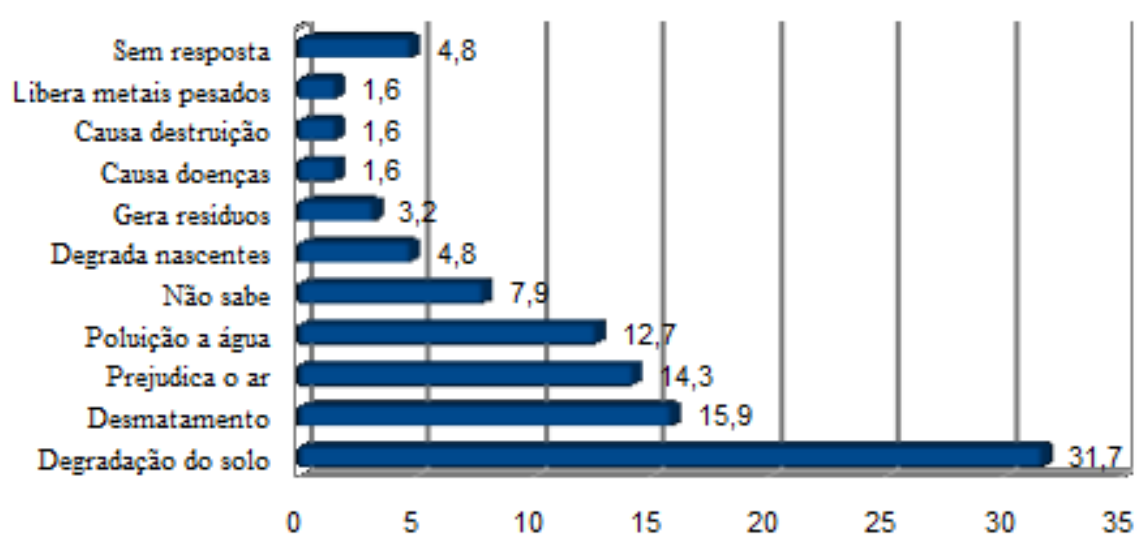

Figura 11 - Impactos da atividade mineradora Fonte: Pesquisa de Campo

Os entrevistados foram questionados se a mineração gera impactos ao meio ambiente. Assim, 56,6\% reconheceram que sim e 29,3\% não souberam responder. Esse último percentual é muito significativo, pois novamente demonstra o desconhecimento dos moradores sobre a atividade, o que se soma à opinião de outros 7,6\% que declararam que a atividade não gera impactos.

Os que identificaram a atividade mineradora como impactante foram solicitados a indicar quais seriam esses impactos. A degradação do solo foi o principal impacto identificado $(31,7 \%)$, seguido pelo desmatamento $(15,9 \%)$. Em terceiro lugar, aparece a poluição do ar $(14,3 \%)$, indicada apenas pelos moradores da área urbana. Quanto a esse aspecto, há uma percepção distorcida dos impactos dessa atividade. Com efeito, no tocante à qualidade do ar, não há prognóstico das alterações significativas dessa qualidade, mas apenas na área de influência direta do empreendimento deverão ser tomadas medidas preventivas quanto à emissão de material particulado (poeiras fugitivas), assim como dos gases de exaustão dos equipamentos, máquinas e veículos envolvidos no processo. A poluição da água também está entre os impactos mais indicados $(12,7 \%)$. Os demais impactos indicados podem ser visualizados na Figura 11.

Esses dados reforçam a necessidade de que, no processo de licenciamento, a população seja esclarecida sobre os reais impactos da atividade e das medidas mitigadoras que serão implementadas. Contudo, o que se verifica na prática é que se a população desconhece previamente tais informações, tão pouco o processo de licenciamento tem se mostrado favorável a superação dessa realidade. Estudos têm apontado severas críticas ao processo de licenciamento, um dos principais instrumentos da Política Nacional de Meio Ambiente, processo este que reproduz a dinâmica do campo ambiental, constituído por posições hierarquizadas e relações de poder desiguais (ZHOURI, 2008). Conforme apontado por Zhouri (2008), esse instrumento apresenta problemas de ordem político-estrutural e procedimental, entre eles, a dificuldade de acesso às informações por parte da população, comprometendo a governança ${ }^{4}$ local sobre os territórios.

A possibilidade de conciliação entre meio ambiente e desenvolvimento, prerrogativa do desenvolvimento sustentável, foi também questionada junto aos moradores de Carmo da

\footnotetext{
4 Governança é aqui entendida como um novo modelo político em que vários atores sociais governamentais e não governamentais, sociedade civil e corporações sistematicamente se juntam para apresentar soluções em novos arranjos societários (ZHOURI, 2008).
} 
Mata. Assim, 46,7\% consideraram que é possível conciliar mineração e preservação ambiental, 23,9\% não souberam responder e $12 \%$ consideraram que não. A percepção da maioria dos moradores acompanha tendência hegemônica no campo das percepções sociais e do imaginário cultural no Brasil, especialmente a partir do final dos anos 1980, segundo a qual não há antagonismo entre crescimento econômico e proteção ambiental, onde ecologia e economia passam a ser parceiras da moderna concepção produtiva (LAYRARGUES, 2006). A partir dessa perspectiva, desenvolvimento sustentável representa um verdadeiro valor cultural disseminado em nossa sociedade, que esconde e mascara aporias e produz um falso consenso, estabelecendo no nível discursivo, uma hegemonia simbólica que dá suporte à sustentabilidade do desenvolvimento (RABELO, 2007).

\subsection{Participação social e hábitos de comunicação}

A participação social também foi investigada e verificou-se que há pouca participação social dos moradores. Apenas $27,5 \%$ declararam participar de alguma organização, grupo ou entidade na cidade. Essa reduzida participação se dá, em sua maioria, em atividades e grupos religiosos, o que se justifica pela presença marcante da religiosidade na cultura local. Em segundo aparecem grupos de juventude (12\%) e irmandades/congado (8\%) que, geralmente, são atividades também ligadas à religiosidade. Quanto à frequência a essas atividades, 76\% disseram participar regularmente.

Finalmente, foram investigados os hábitos de informação dos entrevistados, de forma a contribuir com o planejamento das ações de educação ambiental junto aos moradores. A pesquisa revelou que os principais meios de informação sobre os acontecimentos atuais utilizados pela população de Carmo da Mata são o telejornal (34\%), o jornal escrito (29\%) e a internet $(22 \%)$. Além disso, $11 \%$ declararam ouvir rádio. Revistas foram apontadas por 3\% e outras fontes $2 \%$.

Dessa forma, o telejornal continua a ser o meio mais tradicional de fonte de informação, seguido pelo jornal escrito. Quanto ao último, há que se considerar a limitação do alcance do recurso, considerando a disponibilidade do jornal escrito, sobretudo o local. Ambas as fontes de informação (telejornal e jornal escrito) apresentam percentuais de utilização relativamente próximos, tanto para os moradores da área urbana quanto rural, com uma pequena variação na área rural, onde esses meios são ligeiramente mais expressivos.

Em terceiro lugar aparece a internet (22\%). A utilização da internet tem sido uma forma bastante presente nos hábitos contemporâneos. A pesquisa confirma essa tendência, sobretudo na população urbana $(25 \%)$. Já para a população rural esse acesso é bastante reduzido, apenas $5 \%$ indicaram utilizar.

\section{Considerações Finais}

A pesquisa acerca da percepção ambiental de moradores de Carmo da Mata/MG apresentou importantes indicativos para ações de educação ambiental. Os moradores reconhecem problemas de diversas ordens no município e, entre esses, os problemas ambientais, que foram apontados de forma espontânea por $15 \%$ dos entrevistados.

O lixo foi apresentado como o principal problema ambiental do município (23,6\% dos entrevistados). Na visão dos moradores, esse problema não decorre da ausência ou ineficiência do poder público no recolhimento do lixo, mas, sim, de uma postura inadequada da população. Quando questionada sobre os responsáveis pelos problemas ambientais, a população foi a mais citada (32\%), seguida pela prefeitura (26\%). Por um lado, se o problema do lixo aparece como o principal, por outro a preocupação dos moradores se dirige principalmente ao seu descarte inadequado. Parece não haver uma preocupação ou mesmo o 
conhecimento mais ampliado da questão, uma vez que os moradores se mostraram menos informados com relação à destinação final dos resíduos sólidos no município e, portanto, seu processo de gestão por completo.

Além disso, observa-se uma tendência à centralidade da discussão acerca do lixo doméstico na percepção ambiental dos moradores, ainda que outros problemas tenham sido apontados: esgoto, poluição do ar, desmatamento, arborização, dentre outros. O perigo dessa centralidade se dá na medida em que as discussões ambientais tendem a uma responsabilização excessiva do cidadão (individual) e pela predominância da discussão a respeito dos aspectos técnicos, psicológicos e comportamentais da gestão do lixo, em detrimento de seus aspectos políticos. Dessa forma, medidas técnicas como a reciclagem teriam a capacidade de produzir um efeito ilusório, tranquilizante na consciência dos indivíduos, além de deslocar o eixo da formação da cidadania como atuação coletiva na esfera pública (LAYRARGUES, 2002). Ou seja, os moradores já fariam a sua parte ao se preocupar com o lixo e, assim, a ausência de envolvimento e conhecimento adequado acerca de temáticas como o Plano Diretor, matas ciliares, mineração, florestas, entre outros, seriam mais suportáveis.

A pesquisa revelou, também, que a maioria dos entrevistados não acredita que a população de Carmo da Mata conheça o que é o Plano Diretor e seu papel (58\%). Considerando a importância desse instrumento na regulação do uso e ocupação do território, portanto, na promoção da qualidade urbanística e ambiental do município, essa lei precisa ser apropriada pela população local.

A implantação da atividade mineradora no município foi considerada positiva $(62,5 \%)$, principalmente, em função da geração de empregos. Contudo, o percentual de moradores que não souberam opinar ou não responderam foi elevado, chegando a $26,8 \%$ do total de entrevistados, o que sinaliza o desconhecimento acerca dessa atividade. Isto é reforçado pelo fato de que $27,8 \%$ dos entrevistados, apesar de enxergarem na mineração a capacidade de contribuir para a qualidade de vida da população, não souberam responder quais seriam seus pontos positivos. Os entrevistados foram questionados também se, sob seu entendimento, a mineração gera impactos ao meio ambiente. Dessa forma, 29,3\% não souberam responder, percentual muito significativo que, novamente, demonstra o desconhecimento dos moradores sobre a atividade, o que se soma à opinião de outros 7,6\%, que declararam que a atividade não gera impactos. Além disso, as informações sobre quais seriam esses impactos são distorcidas, sendo indicados impactos inexistentes e desconsiderados outros. Os dados levantados reforçam a necessidade de ações de educação ambiental, que promovam o debate e a participação da população no processo de licenciamento, de forma mais crítica e autônoma, pautada pelos princípios da diversidade cultural e da democratização do acesso aos recursos naturais, em contraposição a uma concepção de gestão ambiental entendida como consenso e gestão dos recursos e dos sujeitos (Zhouri, 2008).

Verificou-se, também, uma percepção predominantemente positiva dos moradores acerca da conciliação entre meio ambiente e desenvolvimento, uma vez que 46,7\% consideraram que é possível conciliar mineração e preservação ambiental. Uma parcela dos moradores $(17,4 \%)$ afirmou que essa conciliação depende, principalmente, de atitudes da empresa, reforçando sua responsabilidade na implantação do empreendimento. Cabe citar que entre todas as indicações, apenas uma, que corresponde a 6,3\%, indica a ação do estado (fiscalização ambiental) para garantir a conciliação entre mineração e preservação ambiental e nenhuma faz menção à atuação dos moradores ou de outros atores como coparticipantes nesse processo.

As ações de educação ambiental para o público estudado também devem levar em consideração que há pouca participação social que, majoritariamente, dá-se em atividades e grupos religiosos. Essas ações, por fim, deverão ser capazes de fomentar a cidadania como 
atuação coletiva na esfera pública.

\section{Referências}

ALONSO, Â.; COSTA, V. Por uma sociologia dos conflitos ambientais no Brasil. In ALIMONDA, H. (Org.). Ecología Política. Naturaleza, Sociedad y Utopía. Buenos Aires: CLACSO, 2002. p. 115-135.

CARSALADE, F. L; ABREU, R. R. Mineração em Minas Gerais: território e paisagem cultural. Anais do I Seminário Internacional de Reconversão de Territórios. Belo Horizonte, 2012. CD-ROM

DIAS, F. F. Percepção da População em relação às empresas de lavra e beneficiamento de bauxita no Município de Poços de Caldas/MG. 2007. 338 f. Tese (Doutorado em Geociências) - Instituto de Geociências, UNICAMP, Campinas, 2007.

FERNANDES, R. S. et al. Uso da percepção ambiental como instrumento de gestão em aplicações ligadas às áreas educacional, social e ambiental. Vitória: UNIVIX/NEPA, 2003. Disponível em: <http://www.ambiente.sp.gov.br/cea/2016/08/01/uso-da-percepcao-ambiental-como-instrumento-degestao-em-aplicacoes-ligadas-as-areas-educacional-social-e-ambiental/>. Acesso em: 13 abr. 2015.

FUKS, M. Arenas de Ação e Debate Públicos: Conflitos Ambientais e a Emergência do Meio Ambiente Enquanto Problema Social no Rio de Janeiro. Dados, Rio de Janeiro, v. 41, n. 1, 1998. Disponível em: 〈http://dx.doi.org/10.1590/S0011-52581998000100003〉. Acesso em: 22 jul. 2016.

FUNDAÇÃO SOS MATA ATLÂNTICA. Caracterização Ambiental por Percepção. Disponível em: <http://migre.me/qQNY9>. Acesso em: 3 de março de 2015.

FUNDAÇÃO EDUCACIONAL DE DIVINÓPOLIS - FUNEDI. Diagnóstico Participativo de Carmo da Mata/MG. Divinópolis: Centro de Referência Técnica em Extensão, Pesquisa e Pós-graduação, 2009. (Inédito).

INSTITUTO BRASILEIRO DE GEOGRAFIA E ESTATÍSTICA - IBGE. Censo Demográfico 2010. Brasília: IBGE, 2010a. Disponível em: 〈http://migre.me/qQNVX〉. Acesso em: 5 mai. 2015.

INSTITUTO BRASILEIRO DE GEOGRAFIA E ESTATÍSTICA - IBGE. Estatísticas do Cadastro Nacional de Empresas 2010. Brasília: IBGE, 2010b. Disponível em: 〈http://migre.me/qQNWU〉. Acesso em: 15 mai. 2015.

LAYRARGUES, P. P. O Cinismo da Reciclagem: o significado ideológico da reciclagem da lata de alumínio e suas implicações para a educação ambiental. In LOUREIRO, C.F.B., LAYRARGUES, P.P.; CASTRO, R. de S. (Orgs.) Educação ambiental: repensando o espaço da cidadania. São Paulo: Cortez, 2002. p. 179-219.

LAYRARGUES, P. P. Muito além da Natureza: Educação Ambiental e Reprodução Social. In Loureiro, C.F.B.; Layrargues, P.P.; Castro, R.C. de (Orgs.) Pensamento complexo, dialética e educação ambiental. São Paulo: Cortez, 2006. p. 72-103.

LOUREIRO, C. F. B. Sustentabilidade e Educação: um olhar da ecologia política. São Paulo: Cortez, 2012.

MARIN, A. A. Pesquisa em educação ambiental e percepção ambiental. Pesquisa em Educação Ambiental, Rio Claro, v. 3, n. 1, p. 203-222, Jun. 2008. Disponível em: <http://www.revistas.usp.br/pea/article/view/30047>. Acesso em: 20 mai. 2015. 
MINAS GERAIS [Estado]. Zoneamento Ecológico Econômico do Estado de Minas Gerais. 2008. Disponível em: <http://www.zee.mg.gov.br/>. Acesso em: 25 abr. de 2015.

RABELO, A. M. P. Aporias da Sustentabilidade: análise da Agenda 21 Brasileira a partir da Teoria Crítica. 2007. 148 f. Dissertação (Mestrado em Educação, Cultura e Organizações Sociais) - Fundação Educacional de Divinópolis - FUNEDI/UEMG, Divinópolis, 2007.

TUAN, Y.-fu. Topofilia - Um estudo da percepção, atitudes e valores do meio ambiente. São Paulo: Difel, 1980.

ZHOURI, A. Justiça ambiental, diversidade cultural e accountability: desafios para a governança ambiental. Rev. bras. Ci. Soc. [online], São Paulo, v.23, n.68, p.97-107, 2008. Disponível em: <http://dx.doi.org/10.1590/S0102-69092008000300007>. Acesso em: 8 ago. 2016. 